\title{
Sound-Action Symbolism
}

\author{
Lari Vainio $^{1,2 *}$ and Martti Vainio ${ }^{1}$ \\ ${ }^{1}$ Phonetics and Speech Synthesis Research Group, Department of Digital Humanities, University of Helsinki, Helsinki, \\ Finland, 'Perception, Action, and Cognition Research Group, Department of Psychology and Logopedics, Faculty of \\ Medicine, University of Helsinki, Helsinki, Finland
}

Recent evidence has shown linkages between actions and segmental elements of speech. For instance, close-front vowels are sound symbolically associated with the precision grip, and front vowels are associated with forward-directed limb movements. The current review article presents a variety of such sound-action effects and proposes that they compose a category of sound symbolism that is based on grounding a conceptual knowledge of a referent in articulatory and manual action representations. In addition, the article proposes that even some widely known sound symbolism phenomena such as the sound-magnitude symbolism can be partially based on similar sensorimotor grounding.

\section{OPEN ACCESS}

Edited by: Andriy Myachykov, Northumbria University, United Kingdom

Reviewed by:

Christoph Scheepers, University of Glasgow,

United Kingdom

Bodo Winter,

University of Birmingham, United Kingdom

Chris F. Westbury, University of Alberta, Canada

*Correspondence: Lari Vainio lari.vainio@gmail.com

Specialty section: This article was submitted to

Language Sciences, a section of the journal Frontiers in Psychology

Received: 01 June 2021

Accepted: 11 August 2021 Published: 14 September 2021

Citation: Vainio L and Vainio M (2021) SoundAction Symbolism.

Front. Psychol. 12:718700. doi: 10.3389/fpsyg.2021.718700
It is also discussed that meaning of suprasegmental speech elements in many instances is similarly grounded in body actions. Sound symbolism, prosody, and body gestures might originate from the same embodied mechanisms that enable a vivid and iconic expression of a meaning of a referent to the recipient.

Keywords: sound symbolism, speech, action, grasping, prosody, gestures

\section{INTRODUCTION}

The core elements of language have evolved nearly exclusively in face-to-face interaction. Typically, in face-to-face communication signaling, a meaning of a referent to the interpreter occurs via verbal and non-verbal communication channels. Verbal signaling consists of spoken words, while non-verbal signaling can utilize oral (e.g., prosody and laughing) and non-oral (e.g., manual gestures, facial expressions, and body postures) forms. Unlike in non-verbal signaling, the relationship between a form of the verbal sign and its meaning has been considered to be essentially arbitrary (e.g., Hockett, 1963). This view highlights that there is nothing inherent, for example, in the word $d o g$ to indicate what it represents. In contrast to this view, the idea of a non-arbitrary relationship between the verbal sign and its meaning has a long history dating back to Plato's Socratic dialogue Cratylus. For example, Peirce (1931) has emphasized that many linguistic signs do not comply with the rule of arbitrariness, but rather iconically represent the referent object, such as in onomatopoeia (e.g., knock, ring, and bang). Later studies have recognized a variety of consistent non-onomatopoeic associations between speech sounds and concepts in which the sound iconically represents some aspect of an object, such as its size or shape (see Lockwood and Dingemanse, 2015 for a review).

This review provides a new theoretical perspective on iconic properties of speech by emphasizing insights derived from views of embodied cognition. The view assumes that many concepts - in particular, those that have relevance to actions performed with body parts - are essentially grounded in action representations (Barsalou, 2008; Pulvermüller and Fadiga, 2010). This view is in line with the motor chauvinist perspective (Sperry, 1952; Wolpert et al., 2001), according to which 
cognitive and perceptual functions have evolved to support motor behavior and hence, to a great degree, still operate in integration with motor processes. This review paper emphasizes that some sound symbolism phenomena can be partially based on conceptual grounding in motor processes. In support of this notion, the paper presents several recently observed sound symbolism effects that are based on an association between speech sound and action (e.g., Vainio et al., 2013, 2015). As an example, front vowels are associated with forward-directed limb movements, and close-front vowels are associated with the precision grip.

The paper proposes that these sound-action symbolism effects are based on tight linkages between the motor processes of articulatory mouth movements and movements of other body parts - the hands in particular. This view holds that, for example, close-front vowels are sound symbolically associated with the precision grip because the meaning of this grip is represented within a motor network that integrates the motor program of the precision grasp with the motor program related to the articulatory gesture of a close-front vowel. In addition, the paper suggests that some commonly reported sound symbolism effects, such as the sound-magnitude effect (Sapir, 1929), which have not been traditionally explained in terms of embodied accounts of cognition, can be also based on conceptual grounding in articulatory and manual sensorimotor processes. The paper further discusses that sound symbolism elements of spoken language have, to some degree, a common embodied origin with gestural and prosodic elements of communication; they are similarly, to a great extent, oriented to communicating ideas in a relatively iconic manner and are also grounded in action representations. However, before getting into the motor perspectives regarding iconic communicative signs, we discuss some basic principles concerning sound symbolism.

\section{SOUND-MEANING ICONICITY}

In addition to direct imitation of sounds as observed in onomatopoeia, many languages have an extensive word class of non-onomatopoeic ideophones (also known as "expressives" or "mimetics") that iconically utilize aspects of the speech signal that go beyond the absolute imitation of sound in order to depict aspects of meaning (Childs, 1994; Mikone, 2001; Schultze-Berndt, 2001; Bodomo, 2006). Often these ideophones include segmental sounds or sound structures that, instead of imitating a sound, are used to express a physical movement, a perceptual property, an affective state, or an action. For example, in Japanese ideophones, the rotation is often represented in the combination of consonants "g"/" $k$ " and "r" (e.g., koro means "a light object rolling"); relatively large mass is represented using a voiced initial consonant (i.e., goro means "a heavy object rolling"); while reduplicating of a word indicates that the event occurs repeatedly (i.e., gorogoro means "a heavy object rolling continuously"; Kita, 1997, 2001; Childs, 2001). Experimental evidence showing, for instance, that participants guess the correct meaning of ideophones of a language unknown to the participant at an above-chance level of accuracy (Iwasaki et al., 2007; Dingemanse et al., 2016) has supported the view that such non-onomatopoeic ideophones present non-arbitrary connections between a vocal sign and meaning.

In this review paper, the term "iconicity" is defined as "the resemblance-based mapping between aspects of form and meaning" (Dingemanse et al., 2015). Onomatopoeic ideophones show "direct iconicity" between the meaning and phonetic aspects of a word, as they include sound elements that imitate the sound of a referent (Masuda, 2007). Based on the same definition, non-onomatopoeic ideophones show "indirect iconicity" between meaning and phonetic aspects of a word, as they associate an impression of a specific sound element of a word to a meaning. The above mentioned observations of direct and indirect iconicity are often labeled under the banner of "sound symbolism," although it is noteworthy that in many, if not most, cases of such linguistic iconicity, the relation between meaning and sound is not based on convention, and many of the sound symbolism phenomena might be rooted in other underlying properties of speech rather than sound, such as the articulatory configurations discussed below.

The existence of iconicity, of course, does not invalidate the premise that arbitrariness is a core property of language. Iconicity and arbitrariness coexist in language, and both have their own functions (Dingemanse et al., 2015). For example, iconicity facilitates language learning (Imai and Kita, 2014; Nielsen and Dingemanse, 2021) as well as the comprehension of communicative signs (Perniss and Vigliocco, 2014; Nielsen and Dingemanse, 2021) and makes communication more vivid (Lockwood and Dingemanse, 2015). However, iconic sounds cannot easily be used to express many, if not most, concepts. Importantly, form-meaning arbitrariness allows language to denote potentially limitless concepts and is particularly useful in conveying abstract meanings (Lupyan and Winter, 2018).

The two most commonly investigated sound-meaning phenomena representing indirect iconicity, both crosslinguistically and in laboratory experiments, are the bouba-kiki effect (also known as the maluma-takete effect) originally observed by Köhler (1929), and the sound-magnitude effect originally observed by Sapir (1929). In the bouba-kiki effect, curved shapes are associated with vowels, which involve lip rounding and/ or tongue backing/lowering (i.e., $[\mathrm{u}],[\mathrm{a}]$, and $[\mathrm{o}]$ ) as well as with the sonorant and voiced bilabial consonants (e.g., [m], [n], and [1]). In contrast, more jagged shapes are associated with relatively high and front vowels (i.e., [i] and [e]) and the voiceless stop consonants (e.g., $[\mathrm{t}],[\mathrm{k}]$, and $[\mathrm{p}]$; Tarte and Barritt, 1971; Ramachandran and Hubbard, 2001; Maurer et al., 2006). This effect has been observed many languages, such as English (Köhler, 1929; Winter and Perlman, 2021), Swahili (Davis, 1961), Himba (Bremner et al., 2013), and Tamil (Ramachandran and Hubbard, 2001). In the sound-magnitude effect, high and front vowels are typically associated with small objects/concepts, while low and back vowels are associated with large objects/concepts (Birch and Erickson, 1958; Thompson and Estes, 2011). Similarly to the bouba-kiki effect, the soundmagnitude effect has been found in many languages, such as English (Johnson, 1967), Korean (Kim, 1977), as well as several other languages (Gebels, 1969; Newmeyer, 1992). 
Although the bouba-kiki effect and the sound-magnitude effect have drawn a great deal of attention from researchers, languages include a much wider variety of sound-meaning correspondences, as also seen in the research on ideophones discussed above. In fact, Blasi et al. (2016) showed that a considerable proportion of the basic words of the world's languages convey non-arbitrary sound-meaning associations. Cross-linguistic research has identified systematic sound-to-meaning mappings in relation to a range of referents, such as brightness (Hirata et al., 2011), colors (Johansson et al., 2020), body parts (Blasi et al., 2016), and emotions (Adelman et al., 2018). These sound-meaning associations can be conceptualized, in general, to arise from associations between particular conceptual and/or perceptual properties of a referent and some quality of the speech production (e.g., their articulatory and/or acoustic features).

Most explanations of sound-meaning associations have emphasized the involvement of cross-modal mappings between two or more processing modalities (e.g., Ramachandran and Hubbard, 2001; Sidhu and Pexman, 2018). In fact, it is well known that processing in separate modalities can be inextricably linked to one another, such as between smell and taste (Stevenson and Oaten, 2010), vision and hearing (McGurk and MacDonald, 1976), vision and action (Franca et al., 2012), or mouth and hand movements (Salmelin and Sams, 2002). As such, soundmeaning associations may be seen as an outcome of the associative pairing of percepts - based, for instance, on their temporal co-occurrence - that are essentially processed in separate systems (Keough et al., 2019). As an example, nasal consonants may occur relatively frequently in the word referring to nose across world languages (Greenberg, 1978; Blasi et al., 2016) because producing nasal consonants resonates in the nasal cavity, implicitly associating the nose with the particular sound of nasal consonants (Urban, 2011). Following this logic, over time, these kinds of systematically occurring cross-modal associations have established themselves in the lexicons of spoken languages.

Regarding the sound-magnitude effect, the effect has been most commonly linked to cross-modal mappings between acoustic properties of specific vowels and small/large objects. This acoustic account highlights that closed vowels typically have higher fundamental frequency $\left(f_{0}\right)$ than open vowels across different languages (Whalen and Levitt, 1995) perhaps because the heightening tongue "pulls on the larynx, and thus increases the tension of the vocal cords" (Ohala and Eukel, 1987, p. 207). Consequently, they can be cross-modally associated with smaller objects because smaller things tend to resonate at higher frequencies (Ohala, 1984; Spence, 2011). For instance, small animals have small vocal apparatuses, resulting in the production of higher frequencies compared to larger animals (Ohala, 1994). In addition to $f_{0}$, empirical evidence shows that the soundmagnitude effect is also linked with the formants $F 1$, which reflects tongue lowering, and $F 2$, which reflects tongue fronting (Fant, 1960), so that larger objects are linked with increased F1 and decreased F2 (Knoeferle et al., 2017; Vainio, 2021). Furthermore, Fitch (2000) has proposed that F1 and F2, and their differential spacing (formant dispersion), which is tied to vocal tract length and body size and decreases from high-front vowels to low-front vowels, might be a better indicator of body size than pitch. In line with this, Ohala (1994) have mentioned that the sound-magnitude effect may also depend on formant dispersion. Hence, research has shown some evidence for supporting the acoustic account of the sound-magnitude effect showing that associating specific vowels with small/large sizes can be attributable to acoustic characteristics of these vowels.

Taken together so far, languages include a wide variety of non-arbitrary associations between vocal signs and meaning that are likely to be attributable to a variety of cross-modal processes. However, the mechanisms behind different sound symbolism phenomena are still largely under debate. For example, although it is indeed intuitive to assume that nasal consonants are associated with nose because they resonate in a nose, conclusive empirical evidence are lacking for this explanation. There is an ongoing debate about the mechanisms underlying even the bouba-kiki and the sound-magnitude effects (Sidhu and Pexman, 2018), which are the most heavily explored sound symbolism effects. In the upcoming sections, we report a number of sound symbolism phenomena that present indirect iconic associations between speech sounds and actions. Based on these findings, we present a novel category of sound symbolism (i.e., sound-action symbolism) and propose the mechanistic underpinnings of this phenomenon.

\section{SOUND-ACTION SYMBOLISM}

Viewed from the perspective of the motor chauvinists (Sperry, 1952; Wolpert et al., 2001) or embodied cognition (Barsalou, 2008; Pulvermüller and Fadiga, 2010), introduced in greater detail in the "Embodiment of Concepts," motor processes can be viewed to contribute to sound symbolism effects. One view regarding how vocal sounds might be associated with actions assumes that certain articulatory gestures mimic or mirror some attribute of an object, such as its size or shape. Thus, a particular vocal sound, which is a consequence of producing the mimicking articulatory gesture, becomes cross-modally connected to the percept of the object. For example, regarding the bouba-kiki effect, some researchers have proposed that rounded vowels are linked to round-edged shapes in the boubakiki effect because lip rounding mirrors the round shape of the object and provides a cross-modal association between the sensorimotor percept of producing the rounded vowels and the visual percept of round-edged shapes (Ramachandran and Hubbard, 2001; Maurer et al., 2006). Regarding the soundmagnitude effect, it has been proposed that in addition to the acoustic account of the effect, introduced in the "Sound-Meaning Iconicity," the effect can be also based on the association between the size of a referent and the sensorimotor percept of producing front-close/back-open vowels (i.e., the articulatory account). This view assumes that, for example, the back-open vowels gesturally mimic largeness of the referent by enlarging the vocal cavity and the front-close vowels gesturally mimic smallness of the referent by reducing the vocal cavity (Sapir, 1929; Ramachandran and Hubbard, 2001). If this view is applied to sound symbolically associating perceived phonemes with 
different magnitudes, it could be assumed that hearing, for example, the vowel [i] results in simulating this vowel in the articulatory motor processes that are involved in producing this vowel by reducing a vocal cavity (D'Ausilio et al., 2009), which in turn leads to decoding this vowel as small.

In line with the view that the bouba-kiki and the soundmagnitude effects are linked to vowel articulation processes, research shows that both of these effects can be observed in vowel production. Firstly, it has been demonstrated that when participants are required to articulate the vowel [i] or [u] according to the size of the round or sharp shapes, the articulation of [i] is facilitated by sharp shapes while [u] is facilitated by round shapes (Vainio et al., 2017b). Correspondingly, the articulation of unround-closed-front vowels is facilitated by processing small spatial and temporal aspects of stimuli, while articulation of round, open, and back vowels is facilitated by processing large spatial and temporal aspects of stimuli (Vainio, 2021). This evidence suggests that articulatory processes are associated with the bouba-kiki effect as well as the soundmagnitude effect.

Given this, it should be however noticed that conclusive and causal evidence for the acoustic as well and articulatory account of the sound-magnitude effect as well as the boubakiki effect is still lacking. Sidhu and Pexman (2018) have provided a comprehensive review of potential sound symbolism mechanisms proposing that there is such wide variability of sound symbolism phenomena that many different sound symbolism effects can be based on different mechanisms, and correspondingly a specific sound symbolism effect can be based on more than one mechanism. As an example, although lip rounding might map rounded vowels with roundedged shapes in the bouba-kiki effect, it has been also shown that participants associate sine-wave versions of the pseudowords maluma and taketa with round and sharp-edged shapes, respectively (Silva and Bellini-Leite, 2020), suggesting that purely acoustic properties of these words can provide characteristics that enable linking them to particular shapes. Similarly, the acoustic and articulatory accounts of the soundmagnitude effect are not mutually exclusive, and it is possible that both of them are valid.

\section{Sound Action Symbolism and Body Movements}

In addition to the above-mentioned sound symbolic interaction between articulation and processing shape and the magnitude elements of a percept, another way in which segmental elements of speech can be iconically associated with actions has been presented by Imai et al. (2008). In their study, the authors created several novel ideophonic verbs expressing different manners of walking along the dimensions of speed and heaviness of movement as well as size of steps. Sound-meaning associations in these novel verbs were based on real sound-meaning associations observed in Japanese ideophones. In addition, the researchers created two video clips for each novel ideophone, with a character walking in a manner that hypothetically either matched or did not match the iconic sound elements of the ideophone. It was found that children as young as 2 years of age were able to detect a sound-action match between ideophones and actions.

In addition to whole-body actions, sound-meaning iconicity can also be linked to hand actions. Many ideophones are often accompanied by gestures imitating the action conveyed by the ideophone (Kunene, 1965). In line with this, it has been shown that co-expressive iconic gestures are frequently produced at the time of vocalizing mimetic words when speakers describe motion and action (Kita, 2001). Similarly, Japanese mimetics are almost always - significantly more frequently than normal verbs - synchronically accompanied by manual gestures (Kita, 1997). These studies suggest that semantic expression of sound symbolic words and manual gestures originates from the same expressive representational processes that are tightly anchored on manual motor system (Kita, 1997). In line with this view, Perlman et al. (2015) have correspondingly suggested that vocal iconicity can originate from the same process of expressing thoughts as iconic gestures.

\section{Grounding Sound Action Symbolism in Reaching and Grasping}

Originally, Ramachandran and Hubbard (2001) took the idea of the linkage between hand actions and sound-meaning associations to a precise level by proposing that articulatory gestures for words such as teeny ([ti:ni]) and petite ([pa'ti:t]) may mimic a precision grip gesture made by the index finger and opposing thumb. This view holds that the sound-meaning association between the concept of smallness and particular phonemes (e.g., the front-close vowels and the voiceless stop consonants) is mediated by cross-domain interaction between manual motor and mouth motor processes. This view is in turn based on the relatively long-lived mouth-gesture theory (Wallace, 1881; Paget, 1944; Hewes, 1973), which assumes that people have an innate tendency to mirror their own as well as others' manipulative and communicative hand movements with analogous movements of the lips, mouth, and the tongue. This tendency can be observed, for example, when a manual cutting action is accompanied by a synchronous jaw opening/ closing movement, or when one tries to thread a needle, and one's finger movements are often accompanied by tongue-thrusts, as noted already by Darwin (1872). The mouth-gesture account holds that, over time, some vocal signs have become systematically linked with elements of manual gestures via this inherited imitative tendency. More recent evidence have supported the view that mouth and hand movements are programmed - to some extent - by combined motor processes (e.g., Arbib, 2005; Gentilucci and Corballis, 2006; Vainio, 2019). For example, the single-cell recordings from macaque monkeys' premotor area F5 (the ventral premotor cortical area 6) contains neurons that discharge when the monkey grasps the object with the mouth or hand (Rizzolatti et al., 1988), and when the monkey observes grasping actions regardless of whether the grasping is executed with the hand or mouth (Gallese et al., 1996). In sum, evidence suggests that certain mouth actions and grasprelated manual actions are programmed within an overlapping sensorimotor network, and as a consequence they mutually influence each other. 
Importantly, our research has supported the proposal that the precision grip action is indeed associated with front-close vowels and voiceless stop consonants. In the paradigm originally reported by Vainio et al. (2013) (see also Tiainen et al., 2017a; Vainio et al., 2018), the participants were required to perform a dual action by simultaneously pronouncing a vowel/consonant and performing a grip response. The participants were visually presented with a vowel (e.g., [i] or [a]) or a consonant (e.g., [t] or $[\mathrm{k}]$ ) colored green or blue while they were holding a precision and power grip response device in their hand. They were asked to pronounce the vowel/consonant immediately after its onset and squeeze either the precision or the power grip device at the same time with the vocalization. In line with the proposal of Ramachandran and Hubbard (2001), the paradigm shows that vocal and manual responses are performed particularly rapidly when there is a hypothesized sound-symbolic match between the vowel/consonant and action (see Figure 1). That is, when the manual response is performed with a precision grip, in comparison to a power grip, and the pronounced vowel is [i] as opposed to [a]. Vocal and manual responses are similarly facilitated when the consonants [t] (an apical stop consonant) and [r] (an alveolar trill) are pronounced with the precision grip response as compared to the power grip response. Tiainen et al. (2017b) showed that although the sound-grip effect was originally observed in speakers of Finnish (i.e., a Finno-Ugric/Uralic language), the same effect can be also observed in speakers of Czech (i.e., a Slavic/Indo-European language), which belongs to a different language family than Finnish.
Complying with the sound-symbolic view of Ramachandran and Hubbard (2001), the sound-grip effect associates the precision grip with the front-close vowel [i] because it is produced by a "small" mouth shape - analogous to the shape of the precision grip - so that the tongue blade is pushed into a high-anterior position. Along the same lines, the precision grip might be associated with the consonants $[t]$ and $[r]$ because articulation of these consonants is achieved by producing a precise closure between the tip of the tongue and the alveolar ridge, which in a sense mimics a finger closure of the precision grip.

Further studies have shown that the connection between the grip type and a specific phoneme or speech sound is not only observed at the level of action production related to a particular articulatory gesture and grip type, but this connection can also manifest itself at the levels of perceptual and conceptual processing. First, vocalization of [ti] and [i] is facilitated solely by preparing to respond with the precision grip, in comparison to the power grip, in absence of an actual response execution (Tiainen et al., 2017a). Second, when participants are presented aurally with the syllables [ti] and [ka] by hampering their discrimination using a noise-mask, a simultaneous grip performance systematically modulates categorization of these syllables: the likelihood of categorizing the syllable as [ti], in comparison to [ka], is significantly increased during precision grip performance (Tiainen et al., 2016). Third, hearing the syllable [ti], in comparison to [ka], facilitates precision grip responses as compared to power grip responses (Vainio et al., 2014). Fourth (see Figure 2), the pronunciation of the vowel [i], in comparison to [a], is facilitated by observing an image

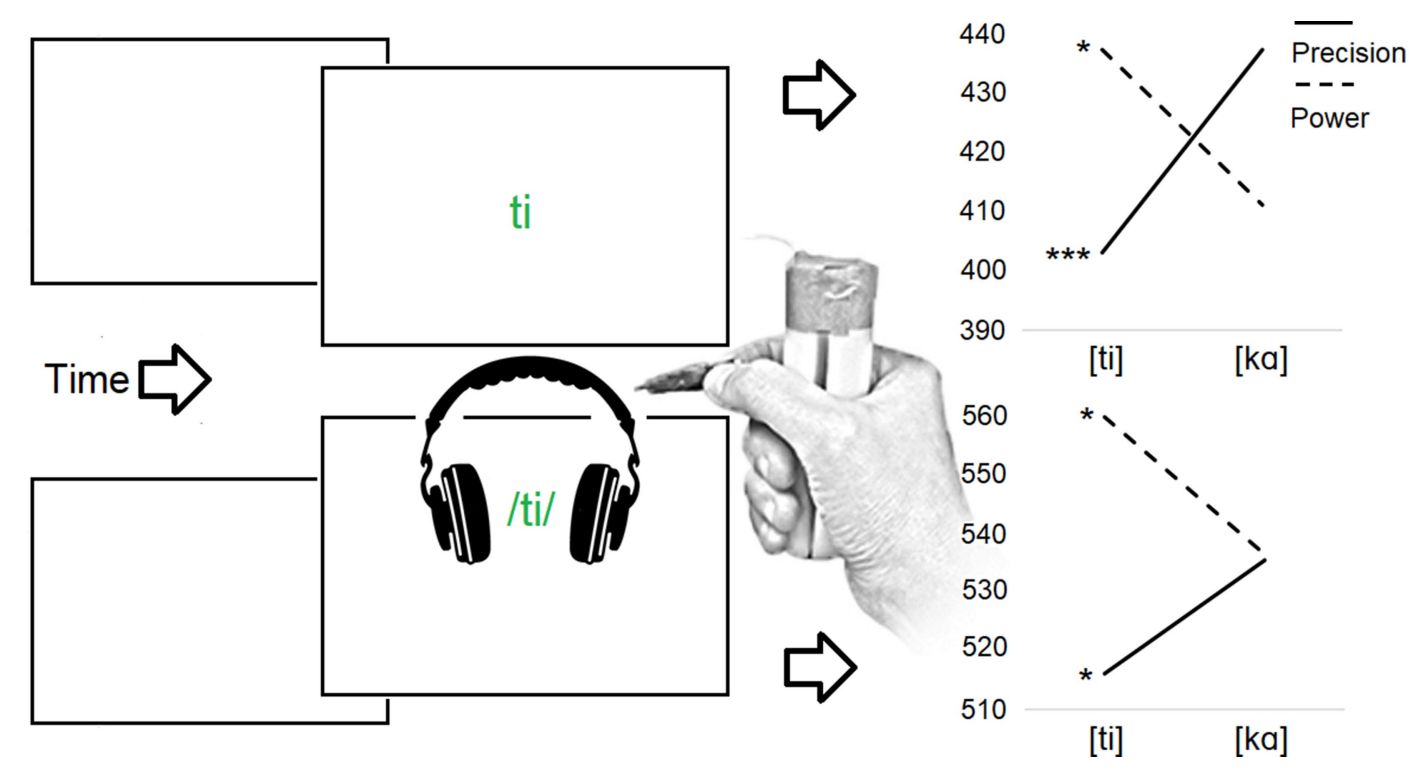

FIGURE 1 | (Above) The reaction time (RT) effect for the study published by Vainio et al. (2013). In the experimental task, the participants were visually presented with a syllable (e.g., [ti] or [ka]). The participants had to respond by squeezing a precision or power grip device according to the color (green/blue) of the syllable while simultaneously pronouncing the syllable. Precision grip responses were performed particularly and rapidly with the syllable [ti], while power grip responses were performed particularly rapidly with the syllable [ka]. (Below) The RT effect for the study published by Vainio et al. (2014). In the experimental task, the participants were aurally presented with the syllable [ti] or [ka] at a high or low pitch. The participants had to perform either precision or power grip response based on the pitch cue. Precision grip responses were performed particularly rapidly with the syllable [ti], while power grip responses were performed particularly rapidly with the syllable [ka]. Asterisks indicate statistically significant differences $\left({ }^{\star \star *} p<0.001 ;{ }^{*} p<0.05\right)$. 
of a hand that is shaped into the precision grip closure as compared to the power grip closure (Vainio et al., 2017a). Fifth, the pronunciation of the vowel [i], in comparison to [a], is facilitated by an image of an object that is graspable by the precision grip (e.g., a pin) as compared to an object graspable with the power grip (e.g., a bottle; Vainio et al., 2019a). As such, the sound-grip effect can be assumed to present a sound-action version of sound symbolism in which a particular vocal sign is iconically associated with a motor, perceptual and conceptual representation of a particular hand action.

The sound-action association, which is similar to that of the sound-grip effect, can also be observed in the shaping of the precision grip during the reaching-to-grasp action. Gentilucci and Campione (2011) asked their participants to reach and grasp an object using the precision grasp. The participants executed the action while they pronounced either [i] or [a]. It was found that production of [a], in comparison to [i], significantly increased finger opening during the grasp action. This outcome systematically associates a specific property of a manual action with a particular vocal sign, hence providing evidence for a sound-action interpretation of sound symbolism. Extending this finding to the context of sound symbolism in the light of mouth-gesture accounts (e.g., Paget, 1944; Ramachandran and Hubbard, 2001), the vowel [a] might be associated with the concept of largeness partially because, analogously to the increased mouth opening associated with producing the vowel [a], grasping large objects requires relatively large openings between the fingers and the thumb.

Research shows that, in addition to systematically linking particular speech sounds to grasping, sounds can be also associated with reach-related directional hand movements. Originally, Wallace (1881) proposed that in many languages, the lip protrusion (i.e., a roundedness of a vowel) is involved in producing words such as go as if a manual pointing gesture was to be replaced by a lip-pointing gesture in articulation. Ramachandran and Hubbard (2001) similarly suggested that, in many languages, articulating the word you involves mouth configuration in which lips are protruded as if the articulatory gesture would imitate manual pointing that is directing outward. The view that emphasizes gestural connectivity between lip and manual pointing is in line with a tendency - observed in many cultures - to accompany, or entirely replace, manual pointing gestures with lip and/or head pointing (Enfield, 2001). However, the cross-linguistic study reported by Wichmann et al. (2010) showed that the front vowel [i] is relatively frequently included in the pronoun that points to the hearer, while the back vowel [a] is more frequently included in the pronoun that points to the speaker himself. If the Wallacian mimicry hypothesis is applied to this finding, it appears that manual pointing could be mirrored in articulating particular deictic words so that the articulatory pointing is produced by pushing (i.e., producing front-close vowels) or pulling (i.e., producing back-open vowels) the tongue.
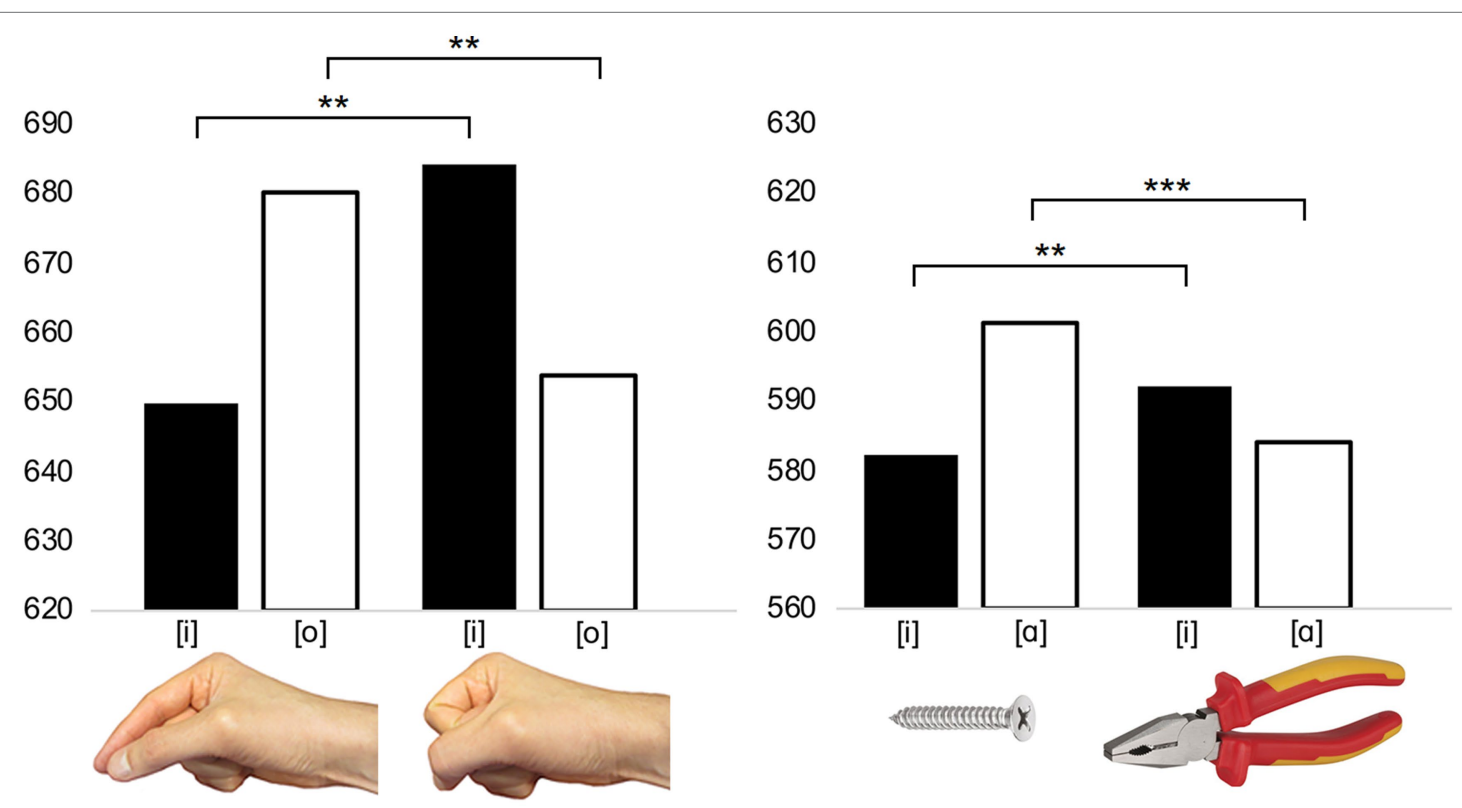

FIGURE 2 | (Left) The RT effect for the study published by Vainio et al. (2017a). In the experimental task, the participants were presented with an image of a handshaped into the precision or power grip. The participants had to respond, as quickly as possible, by vocalizing the [i] or [o] according to the perspective (above/front) of a hand. [i] responses were produced particularly rapidly when the hand was shaped into the precision grip, and [o] was produced particularly rapidly when the hand was shaped into the power grip. (Right) The RT effect for study published by Vainio et al. (2019a). In the experimental task, the participants were presented with an image of an object whose size was compatible with the precision or power grip. The participants had to respond by vocalizing [i] or [a] according to the category of the object (manufactured/natural). [i] responses were produced particularly rapidly when the object's size was compatible with the precision grip, while [a] responses were produced particularly rapidly when the size was compatible with the power grip. Asterisks indicate statistically significant differences $\left({ }^{\star \star \star} p<0.001\right.$; $\left.{ }^{\star *} p<0.01\right)$. 
Our research has provided experimental evidence for the view discussed above that vowel fronting is associated with outward-directed (i.e., away from the body) hand movement, while vowel backing is associated with inward-directed (i.e., toward the body) hand movement (Vainio et al., 2015, 2018). The study used a dual-action paradigm that was a modified version of the sound-grip effect task. In the task, participants were presented visually with a vowel in green or blue, and they were required to perform a push or pull movement with a joystick according to the color, while simultaneously pronouncing the vowel presented. In this sound-reach effect (see Figure 3 for the effect), the vocal and manual responses were facilitated when there was a match between an articulatory fronting/backing property of the vowel and the direction of hand movement. These response benefits were observed when the outward directed hand movements were performed with the vowels that required relative vowel fronting such as [ø] (a rounded front-mid vowel), and when the inward directed hand movements were performed with the vowels that required relative vowel backing such as [o] (a rounded back-mid vowel). In addition, like the sound-grip effect, this sound-reach effect can be found in Finnish and Czech speakers (Tiainen et al., 2017b). Moreover, more recent research has revealed that the same effect can be observed when the manual inward-outward responses are replaced with corresponding leg responses (Vainio et al., 2019b). This suggests that the effect is not restricted to manual processes, but rather the effect can manifest itself in relation to inward-outward movements produced by any effector of the body. Hence, one might propose that the effect essentially operates within inward-outward concepts that are grounded in body movements (Vainio, 2019). Thus, this sound-reach effect presents a sound-action version of sound symbolism in which a particular vocal sign is iconically associated with the direction of a body movement. Below, we describe the sensorimotor processes that might underlie sound symbolism phenomena (i.e., sound-action symbolism) that associate a specific speech sound with an action concept.

\section{EMBODIMENT OF CONCEPTS}

Concepts are traditionally defined as abstract mental entities, different from the motor or perceptual processes (Quillian, 1968; Machery, 2007). This view holds that symbolic cognition is achieved by transforming sensory and motor information into a common amodal representation format (Pylyshyn, 1985). In line with these views, for instance, Mahon and Caramazza (2008) have proposed that all concepts are represented at an abstract, a modal level and motor activation, which is often observed with processing conceptual information, is a by-product of activation spreading from task-related perceptual and/or conceptual processing.

In a sharp contrast, the view that the meaning of certain non-arbitrary vocal signs is grounded in motor processes is consistent with theories of grounded (or embodied) cognition. These theories assume that concepts are represented in the neural networks of distinct brain areas responsible for modality-specific processes of sensory, motor, and emotional systems (Barsalou, 2008; Pulvermüller and Fadiga, 2010). Similarly to the embodied models of cognition, hybrid models also assume that motor and perceptual systems contribute to conceptual representations (Binder and Desai, 2011). However, differently from the accounts of "strong embodiment" (Meteyard et al., 2012), the hybrid models assume that representing conceptual knowledge involves the functioning of semantic hubs that serve to bind distinct modality-specific processes (Kiefer and Pulvermüller, 2012). Although, increasing amount of evidence supports the hybrid models, the debate concerning the nature of conceptual representation is still open (Mahon and Hickok, 2016).

Hybrid and grounded cognition accounts generally hold that motor processes play a key role in representing many concepts; most obviously, those concepts that are associated with actions (Barsalou, 2008). In line with this, studies have shown, for example, that verbs (Hauk et al., 2004) and objects (CreemRegehr and Lee, 2005) that are associated with body movements
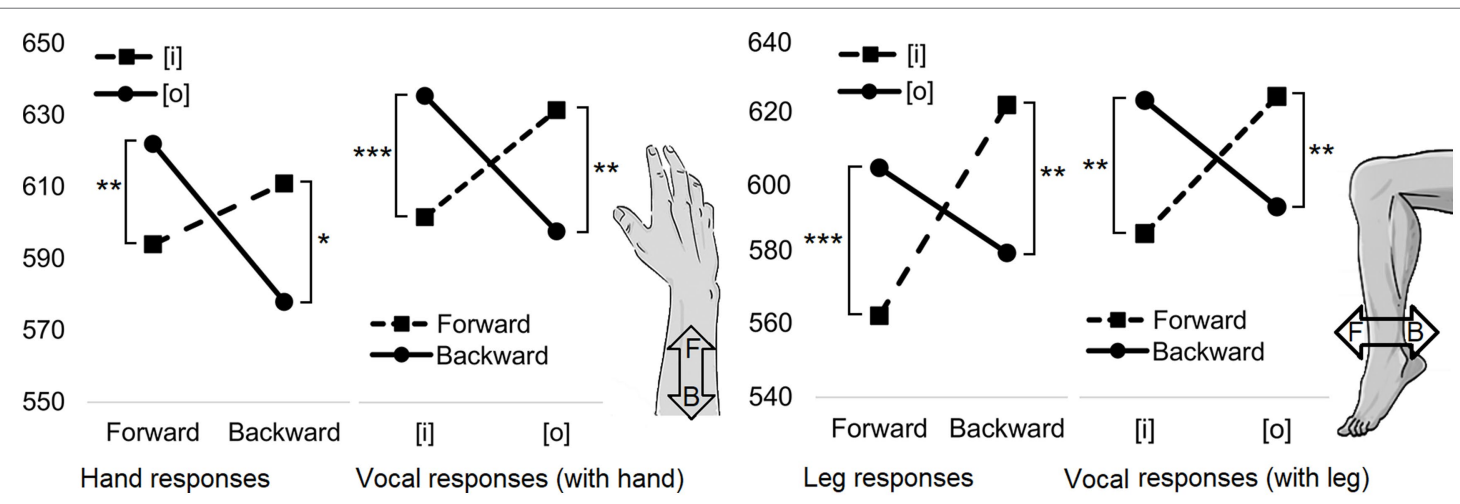

FIGURE 3 | The RT effect for the study published by Vainio et al. (2019b). In the experimental task, the participants were visually presented with the vowel [i] or [o]. The participants had to respond by moving their right hand (the left line graphs) or right leg (the right line graphs) either forward or backward according to the color (green/ blue) of the letter while simultaneously pronouncing the vowel. Limb movements and vocalizations were produced particularly rapidly when the limb was moved forward and the vowel was [i], and when the limb was moved backward and the vowel was [o]. In the images of hand and leg, the letter $F$ (inside the arrow) refers to the word "forward" and the letter B refers to the word "backward." Asterisks indicate statistically significant differences $\left({ }^{* * *} p<0.001 ;{ }^{* *} p<0.01\right.$; and $\left.{ }^{*} p<0.05\right)$. 
(e.g., the word "grasp") are represented in the motor representations of the body parts that are involved in performing these actions. For example, transcranial magnetic stimulation (TMS) research has found corticospinal facilitation associated with hand muscles during passive observation of graspable objects (Franca et al., 2012). Additionally, TMS applied to hand and leg motor representations influence semantic processing of hand and leg related action-words (e.g., "pick" vs. "kick"), respectively, providing causal evidence for embodied views (Pulvermüller et al., 2005).

Some research has suggested that the motor system is fundamentally involved in representing even abstract linguistic concepts such as emotions. According to Pulvermüller (2018), abstract emotional concepts are grounded in concrete actions, such as emotion-related facial expressions, head movements, hand gestures, and body postures. Thus, the meaning of anger could be grounded in action representations of, for example, angry facial expressions, tight postures, and closed fists. This view assumes that grounding the meaning of an abstract emotional concept in concrete actions enables the communication and labeling of inner states that are not accessible as such to other individuals in a robust, shareable, and concrete manner. Even numerical concepts (e.g., "9") have been proposed to be partially represented in relation to actions (Tschentscher et al., 2012; Vainio et al., 2019c). For example, behavioral studies have shown that perceiving relatively small numbers (e.g., 1-4) facilitate responding with the precision grip, while larger numbers (e.g., 6-9) facilitate responding with the power grip (Lindemann et al., 2007; Moretto and Di Pellegrino, 2008). Similarly, when participants grasp an object on which a small or large number is printed, the grasp aperture is increased when the number is large as compared to small numbers (Andres et al., 2004).

The findings related to embodiment of number magnitudes are in line with the A Theory of Magnitude (ATOM) theory (Walsh, 2003), which assumes an overlap in sensorimotor processes that represent conceptual magnitude for the metrics of time, space, and quantity. This account proposes that the fronto-parietal sensorimotor network that is largely responsible for transmitting perceptual information of spatial and temporal metrics to action planning processes (Milner and Goodale, 2008) - planning manual actions, such as grasping, reaching, and pointing in particular - is closely involved in representing magnitude concepts (e.g., small number, near distance, short duration, and small size) in generalized and abstracted form. That is, for instance, the same sensorimotor processes that enable preparing of the precision grip according to the small size of an object also enable the representation of a concept of smallness relative to magnitude dimensions of size, duration, length, and so forth (Bueti and Walsh, 2009).

\section{How Sound Symbolism Could Be Grounded in Motor Processes?}

If concrete action-related concepts as well as loosely actionrelated abstract concepts (e.g., numbers, magnitudes, and emotional concepts) are indeed grounded in actions, one might assume that many sound symbolism phenomena - at least those that are somehow related to actions - are similarly grounded in motor processes. In this light, what makes the ATOM theory potentially relevant in the context of soundmagnitude symbolism is the way in which it assumes that a particular magnitude concept (e.g., smallness) is grounded in the same action representation irrespective of magnitude type (e.g., size, length, and duration). Sound symbolism research has similarly shown that the concept of smallness is associated with the same vowels irrespective of the magnitude dimension. Front-close vowels are sound symbolically associated with quick movement, small size, short spatial, and temporal length as well as near distance, while back-open vowels are associated with slow movement, large size, long spatial, and temporal length as well as far distance (Sapir, 1929; Tanz, 1971; Cuskley, 2013; Rabaglia et al., 2016; Bross, 2018; Vainio, 2021). In addition, just as the ATOM theory grounds generalized magnitude representations in manual actions, in the context of sound symbolism, small magnitudes are linked not only to front-close vowels, but also to precision grasping (Vainio et al., 2013, 2017a, 2019a). Thus, given that mouth gestures and manual gestures are programmed within a combined sensorimotor network (e.g., Arbib, 2005; Gentilucci and Corballis, 2006; Vainio, 2019), it could be assumed - in the light of the ATOM theory - that this mouth-hand network is involved in representing the concept of magnitude in abstracted and generalized from. Therefore, the sound-magnitude effect that associate particular vowels (e.g., [i]) with a particular magnitude (e.g., smallness), might be at least partially based on grounding this magnitude concept in a shared network representing the precision grasp (Vainio et al., 2013), a closed grasp aperture (Gentilucci and Campione, 2011), and a front-close articulatory gesture (Vainio, 2021).

In the nutshell, the evidence for the view that the sensorimotor mouth-hand network is involved in representing the concept of magnitude, and that this sensorimotor grounding of magnitude might provide the neural basis for the sound-magnitude symbolism, is 3 -fold. First, it has been shown that seeing an object that is graspable with the precision grip facilitates precision grip responses, while power grip-compatible objects facilitate power grip responses (Tucker and Ellis, 2001; Ellis et al., 2007). Indeed, an object's size-grasp affordance, signaling how an object could be optimally grasped, is implicitly represented for a viewed object within the parieto-frontal network responsible for planning visually-driven actions (Grèzes et al., 2003; Kourtis et al., 2018), and automatically activates a grasp motor program that is compatible with the object's size (Franca et al., 2012; Makris et al., 2013). Second, evidence suggest a systematic interaction between specific speech sounds and grasping (e.g., Arbib, 2005; Gentilucci and Corballis, 2006; Vainio, 2019). As already mentioned, for instance, the precision grasping is associated with front-close vowels and apical consonants (Vainio et al., 2013, 2018). Third, perceptual and conceptual processing of an object's size-grasp affordances not only recruits grasp representations (Tucker and Ellis, 2001; Franca et al., 2012) but also appears to recruit vowel production processes (Vainio et al., 2019a). Taking this evidence together, it appears that mechanisms that transform size-grasp affordances into 
corresponding grasp- and articulation-related motor programs might provide a neural basis for sound-magnitude symbolism phenomena.

Regarding the sound-reach effect (Vainio et al., 2015), if the embodied account is applied to explain the effect in the light of the ATOM theory, it would be tempting to propose that the front vowels are associated with outward-directed body movements and the back vowels with inward-directed body movements because spatial knowledge of direction is partially represented in the context of body movements that, in particular, integrate directional tongue and hand movements. Hence, it could be concluded that, for example, discrete but semantically overlapping concepts, such as "outward" "forward" and "away from the body" are conceptually represented and generalized within a motor network that programs forward-directed movements of the tongue and the hand in a relatively integrated manner. Consequently, the sound symbolism effect that connects, for example, front vowels to the concept of outward, is to some extent based on the grounding of this concept in action representations of forward-directed body movements performed particularly with the hand and tongue.

Finally, we propose that the sound-action symbolism effects (e.g., Vainio et al., 2013, 2015), in particular, are based on a motor network that connects articulatory gestures to the iconically analogous actions of other body parts, in particular hand actions. This view assumes that these sound-action symbolism effects arise from the grounding meaning of actions in this combined motor network, consequently associating a concept with a specific articulatory gesture (i.e., vowel and/or consonant). In general, following the embodied accounts of conceptual representation, semantic concepts that are associated with actions and body movement (e.g., prehensile hand movements, object affordances, and emotions via body expressions) are grounded to some degree in motor representations. Therefore, it is likely that sound symbolism phenomena that refer to these same concepts are also grounded in motor processes. This is not to say that this motor grounding hypothesis can be applied to sound symbolism effects that are not related to body movements. This section and the "Sound-Action Symbolism" provide some evidence for supporting this view. The next section provides linkages between sound symbolism, prosody, and body gestures. Essentially, the next section emphasizes that similarly to some sound symbolism phenomena, prosody, and communicative body gestures also signal meaning iconically and in an embodied manner.

\section{SUPRASEGMENTAL SOUND SYMBOLISM: ASSOCIATING PROSODY WITH SOUND SYMBOLISM AND BODY MOVEMENTS}

Excepting onomatopoeic words, prosody (i.e., the suprasegmental speech features consisting of voice fundamental frequency, voice intensity and quality, as well as the rhythmic aspects of speech) provides perhaps the most explicit example of iconical conveyance of meaning through the sound properties of oral signaling. For example, prosodic emphasis on a word, produced by increasing its loudness, pitch, and duration, is used to iconically highlight the magnitude of a concept (e.g.", it is SOO cold"). Indeed, empirical evidence shows that English speakers are able to relatively accurately categorize Japanese words when the words are produced with expressive prosody (Kunihira, 1971). Prosody can also cue semantic distinctions like cold-hot or strong-weak (Nygaard et al., 2009; Reinisch et al., 2013). Finally, relevantly for the current proposal, it has been shown that prosody contributes to the effects of sound symbolism (Dingemanse et al., 2016), and prosodic speech events are temporally synchronized to the production of ideophones (Kita, 1997). This evidence show that prosody can iconically convey the meaning of a referent as segmental sound symbolic vocal signs do, and that expressing prosody is fundamentally coupled with expressing sound symbolic speech elements.

Speech is frequently accompanied by gestures (McNeill, 2012). These co-speech gestures, produced particularly by the hands, head, and face, provide a communicative repertoire that can be used to communicate or emphasize the meaning of a referent. Importantly for the current proposal, expressing prosody and sound symbolism are tightly grounded in gestural body movement. Gesturing with the head, eyebrows, and by using beat gestures (i.e., simple and fast movements of the hands) are often observed in relation to the production of suprasegmental speech features, such as stress, intonation, rate, and rhythm (Wagner et al., 2014). For example, the intonation peak, which is observed in question intonation or when providing a prosodic stress on a word, has been shown to frequently co-occur spontaneously in synchrony with gestural hand (Esteve-Gibert and Prieto, 2013; Krivokapic et al., 2015), head (Graf et al., 2002; Esteve Gibert et al., 2014), and eyebrow (Flecha-García, 2010; Swerts and Krahmer, 2010) movements. In addition, prosody that signals an affective state (i.e., emotional prosody) is typically encoded and decoded, in a systematic manner, in relation to emotional facial gestures (Hietanen et al., 1998; Russell et al., 2003) and body postures (Stienen et al., 2011). All this evidence shows that like sound symbolism, prosody is also consistently associated with gestural motor processes.

Research has also shown that there is a great universal tendency in the sound-meaning mapping of prosodic cues. It has been proposed that about $70 \%$ of typologically dissimilar languages have a tendency to use a rising pitch to provide a prosodic cue about interrogation as opposed to affirmation (Bolinger, 1978). As another example, regarding non-linguistic prosody, joy is typically expressed in speech by increased pitch of vocal signaling across different languages, while sadness is expressed by lowering the pitch (Chung, 1999). The universal tendency concerning these phenomena suggests that these sound-meaning associations are not based on convention. As a consequence, the question arises: why a particular prosodic feature (e.g., a rising pitch) signals, across cultures, a particular meaning (e.g., question/joy)?

If viewed through embodied accounts of cognition, signaling a particular meaning, for example, with rising pitch could 
be somehow grounded in motor processes. Indeed, research shows that a rising pitch in question intonation is associated with spontaneous rising of head and eyebrows (McClave, 1991; Horstmann and Ansorge, 2011). There can be several reasons why question is communicated by head rising. For example, head rising might highlight the emotional surprise content of signaling (Bolinger, 1983), or the head rising gesture might develop, in the context of communicating a question, from a request to be picked up by an infant with raised arms and head (Rossano, 2013). However, although these speculations might explain why a question is communicated by the head nod, they do not explain why a question is communicated by a rising pitch in addition to the head nod. It has been proposed that rising pitch in intonation is grounded in the body so that moving the head upward changes the position of the larynx, which pulls on the cricothyroid muscle and consequently changes the pitch (Cwiek and Fuchs, 2019). Hence, the pitch rise in question intonation can be ultimately a consequence of a particular body movement, which gesturally signals question, and has consequently become a universal prosodic standard when signaling a question. This logic could be similarly applied to a rising pitch associated with expressing joy, given that joy is typically expressed by a particular body posture in which head is tilted upwards (Dael et al., 2012). As such, we propose that the meaning of a particular prosodic feature, such as a pitch rise, is essentially grounded in gestural body movements. Intonation and emotional prosody can thus be seen as auditory gestures that iconically simulate body gestures using the vocal apparatus. Taken together, the views and evidence discussed above hold that prosody largely originates from the same representational embodied processes as the sound-action symbolism and communicative body gestures that enable a vivid and iconic expression of the meaning of a referent to the recipient.

\section{CONCLUSION}

Evidence shows that there exists a category of sound symbolism effects - largely neglected in the literature of sound symbolism that associates a vocal sound with a particular body action. This sound-action symbolism appears to operate within the levels of motor, perceptual, and conceptual representations. This is supported, for instance, by the fact that the sound-grip effect - the aforementioned example of sound-action symbolism - is observed relative to the action execution, perception, and conceptualization. Emphasizing the mouth-gesture hypothesis in theorizing these effects, they may essentially be grounded in neural interaction between action representations of mouth and other body parts, the hands in particular. That is, the sound-action symbolism effects might arise from grounding the meaning of actions in the motor

\section{REFERENCES}

Adelman, J. S., Estes, Z., and Cossu, M. (2018). Emotional sound symbolism: languages rapidly signal valence via phonemes. Cognition 175, 122-130. doi: 10.1016/j.cognition.2018.02.007

Andres, M., Davare, M., Pesenti, M., Olivier, E., and Seron, X. (2004). Number magnitude and grip aperture interaction. Neuroreport 15, 2773-2777. network combining articulatory representations with action representations of other body parts, consequently associating a concept with a specific articulatory gesture (i.e., vowel and/or consonant). These views of sound-action phenomena are in line with embodied views of cognition, according to which iconicity provides the mechanism for the grounding of language in sensorimotor systems (Perniss and Vigliocco, 2014).

Moreover, we propose that not only are sound-action symbolism phenomena based on these embodiment mechanisms, but also that some sound symbolism effects that have not been traditionally explained in terms of embodied accounts of cognition (e.g., the sound-magnitude symbolism) can be also based on the grounding of conceptual representations in sensorimotor processes. Furthermore, in the light of the motor chauvinist perspective, the paper emphasizes that sound symbolism, prosody, and body gestures might have a common origin in expressing ideas using utterances and body movements in order to communicate a meaning of a referent in an iconic manner.

Finally, for sake of verifying the view that the sound-grip effect is indeed based on the same sound symbolism processes as the sound-magnitude effect, future studies should investigate the sound-grip effect in a systematic manner in order to show that the same consonants that are associated with small/large objects in the sound-magnitude symbolism are also associated with the precision/power grip responses, respectively. Moreover, although the sound-action symbolism effects introduced in this review present clear examples of sound-meaning iconicity, they request for future cross-linguistic research on whether these sound-action phenomena have established themselves in the lexicons of spoken languages. As an example, it should be investigated whether words that refer to precision griprelated concepts contain more frequently front-close vowels than words that refer to power grip-related concepts. In addition, future research should explore whether motor processes of mouth and/or hand provide causal effect on sound symbolic mapping of small/large sizes with specific vowels, for example, by temporarily disrupting hand and/or mouth motor processes using repetitive Transcranial Magnetic Stimulation (rTMS), while participants carry out a sound symbolism tasks. Finally, the proposal that prosodic cues could be also grounded in motor processes request for future research.

\section{AUTHOR CONTRIBUTIONS}

LV and MV played a central role in writing this manuscript and contributed equally to the new perspectives of the manuscript. All authors contributed to the article and approved the submitted version. 105-124. doi: 10.1017/S0140525X05000038

Barsalou, L. W. (2008). Grounded cognition. Annu. Rev. Psychol. 59, 617-645. doi: 10.1146/annurev.psych.59.103006.093639

Binder, J. R., and Desai, R. H. (2011). The neurobiology of semantic memory. Trends Cogn. Sci. 15, 527-536. doi: 10.1016/j.tics.2011.10.001 
Birch, D., and Erickson, M. (1958). Phonetic symbolism with respect to three dimensions from the semantic differential. J. Gen. Psychol. 58, 291-297. doi: 10.1080/00221309.1958.9920401

Blasi, D. E., Wichmann, S., Hammarström, H., Stadler, P. F., and Christiansen, M. H. (2016). Sound-meaning association biases evidenced across thousands of languages. Proc. Natl. Acad. Sci. 113, 10818-10823. doi: 10.1073/pnas.1605782113

Bodomo, A. (2006). "The structure of ideophones in African and Asian languages: the case of Dagaare and Cantonese." in Selected Proc. 35th Annual Conf. on African linguistics, Harvard University, Cambridge, MA; April 2-4, 2006. eds. J. Mugane, J. P. Hutchison and D. A. Worman (Somerville, MA: Cascadilla Proceedings Project), 203-213.

Bolinger, D. (1978). Intonation across languages. Univ. Human Lang. 2, 471-524.

Bolinger, D. (1983). Intonation and gesture. Am. Speech 58, 156-174. doi: $10.2307 / 455326$

Bremner, A. J., Caparos, S., Davidoff, J., de Fockert, J., Linnell, K. J., and Spence, C. (2013). "Bouba" and "Kiki" in Namibia? A remote culture make similar shape-sound matches, but different shape-taste matches to westerners. Cognition 126, 165-172. doi: 10.1016/j.cognition.2012.09.007

Bross, F. (2018). "Cognitive associations between vowel length and object size: A new feature contributing to a bouba/kiki effect." in Proceedings of the Conference on Phonetics and Phonology; September 28-29, 2018 (Berlin, Germany: Humboldt-Universität), 17-20.

Bueti, D., and Walsh, V. (2009). The parietal cortex and the representation of time, space, number and other magnitudes. Philos. Trans. R. Soc. Lond. B Biol. Sci. 364, 1831-1840. doi: 10.1098/rstb.2009.0028

Childs, G. T. (1994). "Sound symbolism" in The Oxford Handbook of the Word. eds. J. J. Ohala, L. Hinton and J. Nichols (Cambridge: CUP).

Childs, G. T. (2001). Research on ideophones, whither hence?: The need for a social theory of ideophones. Typolog. Stud. Lang. 44, 63-74. doi: 10.1075/tsl.44.06chi

Chung, S. J. (1999). "Vocal expression and perception of emotion in Korean." in 14th International Conference of Phonetic Sciences; August 1-7, 1999; San Fransisco, USA.

Creem-Regehr, S. H., and Lee, J. N. (2005). Neural representations of graspable objects: are tools special? Cogn. Brain Res. 22, 457-469. doi: 10.1016/j. cogbrainres.2004.10.006

Cuskley, C. (2013). Mappings between linguistic sound and motion. Public J. Semiotics 5, 39-62. doi: 10.37693/pjos.2013.5.9651

Cwiek, A., and Fuchs, S. (2019). "Iconic prosody is rooted in sensori-motor properties: fundamental frequency and the vertical space." in Proceedings of the 41st Annual Meeting of the Cognitive Science Society; July 24-27, 2019; Montreal, Canada, 1572-1578.

Dael, N., Mortillaro, M., and Scherer, K. R. (2012). Emotion expression in body action and posture. Emotion 12:1085. doi: 10.1037/a0025737

Darwin, C. (1872). The Expression of the Emotions in Man and Animals. London: J. Murray

D’Ausilio, A., Pulvermüller, F., Salmas, P., Bufalari, I., Begliomini, C., and Fadiga, L. (2009). The motor somatotopy of speech perception. Curr. Biol. 19, 381-385. doi: 10.1016/j.cub.2009.01.017

Davis, R. (1961). The fitness of names to drawings. A cross-cultural study in Tanganyika. Br. J. Psychol. 52, 259-268.

Dingemanse, M., Blasi, D. E., Lupyan, G., Christiansen, M. H., and Monaghan, P. (2015). Arbitrariness, iconicity, and systematicity in language. Trends Cogn. Sci. 19, 603-615. doi: 10.1016/j.tics.2015.07.013

Dingemanse, M., Schuerman, W., Reinisch, E., Tufvesson, S., and Mitterer, H. (2016). What sound symbolism can and cannot do: testing the iconicity of ideophones from five languages. Language 92, e117-e133. doi: 10.1353/ lan.2016.0034

Ellis, R., Tucker, M., Symes, E., and Vainio, L. (2007). Does selecting one visual object from several require inhibition of the actions associated with nonselected objects? J. Exp. Psychol. Hum. Percept. Perform. 33:670. doi: 10.1037/0096-1523.33.3.670

Enfield, N. J. (2001). 'Lip-pointing': A discussion of form and function with reference to data from Laos. Gesture 1, 185-211. doi: 10.1075/gest.1.2.06enf

Esteve Gibert, N., Borràs Comes, J. M., Swerts, M., and Prieto Vives, P. (2014). "Head gesture timing is constrained by prosodic structure." in Speech Prosody 2014; May 20-23, 2014; Dublin, Ireland, 1-5.

Esteve-Gibert, N., and Prieto, P. (2013). Prosodic structure shapes the temporal realization of intonation and manual gesture movements. J. Speech Lang. Hear. Res. 56, 850-864. doi: 10.1044/1092-4388(2012/12-0049)
Fant, G. (1960). Acoustic Theory of Speech Production. The Hague: Mouton Fitch, W. T. (2000). The evolution of speech: a comparative review. Trends Cogn. Sci. 4, 258-267. doi: 10.1016/S1364-6613(00)01494-7

Flecha-García, M. L. (2010). Eyebrow raises in dialogue and their relation to discourse structure, utterance function and pitch accents in English. Speech Comm. 52, 542-554. doi: 10.1016/j.specom.2009.12.003

Franca, M., Turella, L., Canto, R., Brunelli, N., Allione, L., Andreasi, N. G., et al. (2012). Corticospinal facilitation during observation of graspable objects: a transcranial magnetic stimulation study. PLoS One 7:e49025. doi: 10.1371/ journal.pone. 0049025

Gallese, V., Fadiga, L., Fogassi, L., and Rizzolatti, G. (1996). Action recognition in the premotor cortex. Brain 119, 593-609. doi: 10.1093/brain/119.2.593

Gebels, G. (1969). An investigation of phonetic symbolism in different cultures. J. Verbal Learn. Verbal Behav. 8, 310-312. doi: 10.1016/S0022-5371(69)80083-6

Gentilucci, M., and Campione, G. C. (2011). Do postures of distal effectors affect the control of actions of other distal effectors? Evidence for a system of interactions between hand and mouth. PLoS One 6:e19793. doi: 10.1371/ journal.pone. 0019793

Gentilucci, M., and Corballis, M. C. (2006). From manual gesture to speech: a gradual transition. Neurosci. Biobehav. Rev. 30, 949-960. doi: 10.1016/j. neubiorev.2006.02.004

Graf, H. P., Cosatto, E., Strom, V., and Huang, F. J. (2002). "Visual prosody: Facial movements accompanying speech." in Proceedings of Fifth IEEE International Conference on Automatic Face Gesture Recognition; May 20-21, 2002; Washington, DC, 396-401.

Greenberg, J. H. (1978). "Introduction" in Universals of Language, Volume 2: Phonology. eds. J. H. Greenberg, C. A. Ferguson and E. A. Moravcsik (Redwood City, CA: Stanford University Press), 1-8.

Grèzes, J., Tucker, M., Armony, J., Ellis, R., and Passingham, R. E. (2003). Objects automatically potentiate action: an fMRI study of implicit processing Eur. J. Neurosci. 17, 2735-2740. doi: 10.1046/j.1460-9568.2003.02695.x

Hauk, O., Johnsrude, I., and Pulvermüller, F. (2004). Somatotopic representation of action words in human motor and premotor cortex. Neuron 41, 301-307. doi: $10.1016 /$ S0896-6273(03)00838-9

Hewes, G. W. (1973). Primate communication and the gestural origin of language. Curr. Anthropol. 14, 5-24. doi: 10.1086/201401

Hietanen, J. K., Surakka, V., and Linnankoski, I. (1998). Facial electromyographic responses to vocal affect expressions. Psychophysiology 35, 530-536. doi: $10.1017 /$ S0048577298970445

Hirata, S., Ukita, J., and Kita, S. (2011). Implicit phonetic symbolism in voicing of consonants and visual lightness using Garner's speeded classification task. Percept. Mot. Skills 113, 929-940. doi: 10.2466/15.21.28. PMS.113.6.929-940

Hockett, C. (1963). "The problem of universals in language" in Universals of Language. ed. J. Greenberg (Cambridge, MA: MIT Press), 1-22.

Horstmann, G., and Ansorge, U. (2011). Compatibility between tones, head movements, and facial expressions. Emotion 11:975. doi: 10.1037/a0023468

Imai, M., and Kita, S. (2014). The sound symbolism bootstrapping hypothesis for language acquisition and language evolution. Philos. Trans. R. Soc. Lond. B Biol. Sci. 369:20130298. doi: 10.1098/rstb.2013.0298

Imai, M., Kita, S., Nagumo, M., and Okada, H. (2008). Sound symbolism facilitates early verb learning. Cognition 109, 54-65. doi: 10.1016/j. cognition.2008.07.015

Iwasaki, N., David, P. V., and Gabriella, V. (2007). What do English speakers know about Gera-Gera and yota-yota?: A cross-linguistic investigation of mimetic words of laughing and walking. Japanese language education around the globe. Jpn. Lang. Educ. Globe 17, 53-78.

Johansson, N., Anikin, A., and Aseyev, N. (2020). Color sound symbolism in natural languages. Lang. Cogn. 12, 56-83. doi: 10.1017/langcog.2019.35

Johnson, R. C. (1967). Magnitude symbolism of English words. J. Verbal Learn. Verbal Behav. 6, 508-511. doi: 10.1016/S0022-5371(67)80008-2

Keough, M., Derrick, D., and Gick, B. (2019). Cross-modal effects in speech perception. Annu. Rev. Linguist. 5, 49-66. doi: 10.1146/annurevlinguistics-011718-012353

Kiefer, M., and Pulvermüller, F. (2012). Conceptual representations in mind and brain: theoretical developments, current evidence and future directions. Cortex 48, 805-825. doi: 10.1016/j.cortex.2011.04.006

Kim, K. O. (1977). Sound symbolism in Korean. J. Linguist. 13, 67-75. doi: $10.1017 /$ S0022226700005211 
Kita, S. (1997). Two-dimensional semantic analysis of Japanese mimetics. Linguistics 35, 379-415.

Kita, S. (2001). Semantic schism and interpretive integration in Japanese sentences with a mimetic: A reply to Tsujimura. Linguistics 39, 419-436. doi: 10.1515/ ling.2001.017

Knoeferle, K., Li, J., Maggioni, E., and Spence, C. (2017). What drives sound symbolism? Different acoustic cues underlie sound-size and sound-shape mappings. Sci. Rep. 7:5562. doi: 10.1038/s41598-017-05965-y

Köhler, W. (1929). Gestalt Psychology. New York: Liveright.

Kourtis, D., Vandemaele, P., and Vingerhoets, G. (2018). Concurrent cortical representations of function-and size-related object affordances: An fMRI study. Cogn. Affect. Behav. Neurosci. 18, 1221-1232. doi: 10.3758/ s13415-018-0633-1

Krivokapic, J., Tiede, M., and Tyrone, M. E. (2015). Kinematic properties of concurrently recorded speech and body gestures and their relationship to prosodic structure. J. Acoust. Soc. Am. 137:2269. doi: 10.1121/1.4920285

Kunene, D. P. (1965). The ideophone in southern Sotho. J. African Lang. 4, 19-39.

Kunihira, S. (1971). Effects of the expressive voice on phonetic symbolism. J. Verbal Learn. Verbal Behav. 10, 427-429. doi: 10.1016/S0022-5371(71)80042-7

Lindemann, O., Abolafia, J. M., Girardi, G., and Bekkering, H. (2007). Getting a grip on numbers: numerical magnitude priming in object grasping. $J$. Exp. Psychol. Hum. Percept. Perform. 33:1400. doi: 10.1037/0096-1523.33.6.1400

Lockwood, G., and Dingemanse, M. (2015). Iconicity in the lab: A review of behavioral, developmental, and neuroimaging research into sound-symbolism. Front. Psychol. 6:1246. doi: 10.3389/fpsyg.2015.01246

Lupyan, G., and Winter, B. (2018). Language is more abstract than you think, or, why aren't languages more iconic? Philos. Trans. R. Soc. Lond. B, Biol. Sci. 373:20170137. doi: 10.1098/rstb.2017.0137

Machery, E. (2007). Concept empiricism: a methodological critique. Cognition 104, 19-46. doi: 10.1016/j.cognition.2006.05.002

Mahon, B. Z., and Caramazza, A. (2008). A critical look at the embodied cognition hypothesis and a new proposal for grounding conceptual content. J. Physiol. Paris 102, 59-70. doi: 10.1016/j.jphysparis.2008.03.004

Mahon, B. Z., and Hickok, G. (2016). Arguments about the nature of concepts: symbols, embodiment, and beyond. Psychon. Bull. Rev. 23, 941-958. doi: 10.3758/s13423-016-1045-2

Makris, S., Grant, S., Hadar, A. A., and Yarrow, K. (2013). Binocular vision enhances a rapidly evolving affordance priming effect: behavioural and TMS evidence. Brain Cogn. 83, 279-287. doi: 10.1016/j.bandc.2013.09.004

Masuda, K. (2007). "The physical basis for phonological iconicity" in Insistent Images. eds. E. Tabakowska, C. Ljungberg and O. Fischer (Philadephia: John Benjamins), 57-72.

Maurer, D., Pathman, T., and Mondloch, C. J. (2006). The shape of boubas: sound-shape correspondences in toddlers and adults. Dev. Sci. 9, 316-322. doi: $10.1111 /$ j.1467-7687.2006.00495.x

McClave, E. (1991). Intonation and Gesture. Washington DC: Doctoral Dissertation, Georgetown University

McGurk, H., and MacDonald, J. (1976). Hearing lips and seeing voices. Nature 264, 746-748. doi: 10.1038/264746a0

McNeill, D. (2012). How Language Began: Gesture and Speech in Human Evolution. Cambridge: Cambridge University Press.

Meteyard, L., Cuadrado, S. R., Bahrami, B., and Vigliocco, G. (2012). Coming of age: A review of embodiment and the neuroscience of semantics. Cortex 48, 788-804. doi: 10.1016/j.cortex.2010.11.002

Mikone, E. (2001). Ideophones in the Balto-Finnic languages. Typolog. Stud. Lang. 44, 223-234. doi: 10.1075/tsl.44.18mik

Milner, A. D., and Goodale, M. A. (2008). Two visual systems re-viewed. Neuropsychologia 46, 774-785. doi: 10.1016/j.neuropsychologia.2007.10.005

Moretto, G., and Di Pellegrino, G. (2008). Grasping numbers. Exp. Brain Res. 188, 505-515. doi: 10.1007/s00221-008-1386-9

Newmeyer, F. J. (1992). Iconicity and generative grammar. Language 68, 756796. doi: 10.1353/lan.1992.0047

Nielsen, A. K., and Dingemanse, M. (2021). Iconicity in word learning and beyond: a critical review. Lang. Speech 64, 52-72. doi: 10.1177/0023830920914339

Nygaard, L. C., Herold, D. S., and Namy, L. L. (2009). The semantics of prosody: acoustic and perceptual evidence of prosodic correlates to word meaning. Cogn. Sci. 33, 127-146. doi: 10.1111/j.1551-6709.2008.01007.x

Ohala, J. J. (1984). An ethological perspective on common cross-language utilization of $\mathrm{F}_{0}$ of voice. Phonetica 41, 1-16. doi: 10.1159/000261706
Ohala, J. J. (1994). "The frequency code underlies the sound-symbolic use of voice pitch" in Sound Symbolism. eds. L. Hinton, J. Nichols and J. Ohala (Cambridge, UK: Cambridge University Press), 325-347.

Ohala, J. J., and Eukel, B. W. (1987). "Explaining the intrinsic pitch of vowels" in In Honour of Ilse Lehiste. eds. R. Channon and L. Shockey (Dordrecht: Foris), 207-215.

Paget, R. A. (1944). The origin of language. Science 99, 14-15. doi: 10.1126/ science.99.2558.14

Peirce, C.S. (1931). Collected Papers. Principles of Philosophy, Vol. 1. Cambridge: Harvard University Press

Perlman, M., Dale, R., and Lupyan, G. (2015). Iconicity can ground the creation of vocal symbols. R. Soc. Open Sci. 2:150152. doi: 10.1098/rsos.150152

Perniss, P., and Vigliocco, G. (2014). The bridge of iconicity: from a world of experience to the experience of language. Philos. Trans. R. Soc. Lond. B Biol. Sci. 369:20130300. doi: 10.1098/rstb.2013.0300

Pulvermüller, F. (2018). The case of CAUSE: neurobiological mechanisms for grounding an abstract concept. Philos. Trans. R. Soc. Lond. B Biol. Sci. 373:20170129. doi: 10.1098/rstb.2017.0129

Pulvermüller, F., and Fadiga, L. (2010). Active perception: sensorimotor circuits as a cortical basis for language. Nat. Rev. Neurosci. 11, 351-360. doi: 10.1038/nrn2811

Pulvermüller, F., Hauk, O., Nikulin, V. V., and Ilmoniemi, R. J. (2005). Functional links between motor and language systems. Eur. J. Neurosci. 21, 793-797. doi: 10.1111/j.1460-9568.2005.03900.x

Pylyshyn, Z. W. (1985). Computation and Cognition: Toward a Foundation for Cognitive Science. Cambridge: The MIT Press.

Quillian, M. R. (1968). "Semantic memory," in Semantic Information Processing. ed. M. Minsky (Cambridge, MA: MIT Press), 227-270.

Rabaglia, C. D., Maglio, S. J., Krehm, M., Seok, J. H., and Trope, Y. (2016). The sound of distance. Cognition 152, 141-149. doi: 10.1016/j. cognition.2016.04.001

Ramachandran, V. S., and Hubbard, E. M. (2001). Synaesthesia--a window into perception, thought and language. J. Conscious. Stud. 8, 3-34.

Reinisch, E., Jesse, A., and Nygaard, L. C. (2013). Tone of voice guides word learning in informative referential contexts. Q. J. Exp. Psychol. 66, 1227-1240. doi: 10.1080/17470218.2012.736525

Rizzolatti, G., Camarda, R., Fogassi, L., Gentilucci, M., Luppino, G., and Matelli, M. (1988). Functional organization of inferior area 6 in the macaque monkey. Exp. Brain Res. 71, 491-507. doi: 10.1007/BF00248742

Rossano, F. (2013). "Gaze in conversation" in The Handbook of Conversation Analysis. eds. T. Stivers and J. Sidnell (Chichester, UK: Wiley- Blackwell), 308-329.

Russell, J. A., Bachorowski, J. A., and Fernández-Dols, J. M. (2003). Facial and vocal expressions of emotion. Annu. Rev. Psychol. 54, 329-349. doi: 10.1146/ annurev.psych.54.101601.145102

Salmelin, R., and Sams, M. (2002). Motor cortex involvement during verbal versus non-verbal lip and tongue movements. Hum. Brain Mapp. 16, 81-91. doi: 10.1002/hbm.10031

Sapir, E. (1929). A study in phonetic symbolism. J. Exp. Psychol. 12:225. doi: $10.1037 / \mathrm{h} 0070931$

Schultze-Berndt, E. (2001). Ideophone-like characteristics of uninflected predicates in Iaminjung (Australia)'. Ideophones 44:355. doi: 10.1075/tsl.44.27sch

Sidhu, D. M., and Pexman, P. M. (2018). Five mechanisms of sound symbolic association. Psychon. Bull. Rev. 25, 1619-1643. doi: 10.3758/s13423-017-1361-1

Silva, D. M. R., and Bellini-Leite, S. C. (2020). Cross-modal correspondences in sine wave: speech versus non-speech modes. Atten. Percept. Psychophysiol. 82, 944-953. doi: 10.3758/s13414-019-01835-Z

Spence, C. (2011). Crossmodal correspondences: a tutorial review. Atten. Percept. Psychophysiol. 73, 971-995. doi: 10.3758/s13414-010-0073-7

Sperry, R. W. (1952). Neurology and the mind-brain problem. Am. Sci. 40, 291-312.

Stevenson, R. J., and Oaten, M. J. (2010). Sweet odours and sweet tastes are conflated in memory. Acta Psychol. 134, 105-109. doi: 10.1016/j. actpsy.2010.01.001

Stienen, B. M., Tanaka, A., and de Gelder, B. (2011). Emotional voice and emotional body postures influence each other independently of visual awareness. PLoS One 6:e25517. doi: 10.1371/journal.pone.0025517

Swerts, M., and Krahmer, E. (2010). Visual prosody of newsreaders: effects of information structure, emotional content and intended audience on facial expressions. J. Phon. 38, 197-206. doi: 10.1016/j.wocn.2009.10.002 
Tanz, C. (1971). Sound symbolism in words relating to proximity and distance. Lang. Speech 14, 266-276. doi: 10.1177/002383097101400307

Tarte, R. D., and Barritt, L. S. (1971). Phonetic symbolism in adult native speakers of English: three studies. Lang. Speech 14, 158-168. doi: 10.1177/002383097101400206

Thompson, P. D., and Estes, Z. (2011). Sound symbolic naming of novel objects is a graded function. Q. J. Exp. Psychol. 64, 2392-2404. doi: 10.1080/17470218.2011.605898

Tiainen, M., Lukavský, J., Tiippana, K., Vainio, M., Šimko, J., Felisberti, F., et al. (2017b). Connections of grasping and horizontal hand movements with articulation in Czech speakers. Front. Psychol. 8:516. doi: 10.3389/fpsyg.2017.00516

Tiainen, M., Tiippana, K., Vainio, M., Komeilipoor, N., and Vainio, L. (2017a). Interaction in planning vocalizations and grasping. Q. J. Exp. Psychol. 70, 1590-1602. doi: 10.1080/17470218.2016.1195416

Tiainen, M., Tiippana, K., Vainio, M., Peromaa, T., Komeilipoor, N., and Vainio, L. (2016). Selective influences of precision and power grips on speech categorization. PLoS One 11:e0151688. doi: 10.1371/journal.pone.0151688

Tschentscher, N., Hauk, O., Fischer, M. H., and Pulvermüller, F. (2012). You can count on the motor cortex: finger counting habits modulate motor cortex activation evoked by numbers. NeuroImage 59, 3139-3148. doi: 10.1016/j.neuroimage.2011.11.037

Tucker, M., and Ellis, R. (2001). The potentiation of grasp types during visual object categorization. Vis. Cogn. 8, 769-800. doi: 10.1080/13506280042000144

Urban, M. (2011). Conventional sound symbolism in terms for organs of speech: a cross-linguistic study. Folia Linguistica 45, 199-213. doi: 10.1515/flin.2011.007

Vainio, L. (2019). Connection between movements of mouth and hand: perspectives on development and evolution of speech. Neurosci. Biobehav. Rev. 100, 211-223. doi: 10.1016/j.neubiorev.2019.03.005

Vainio, L. (2021). Magnitude sound symbolism influences vowel production. J. Mem. Lang. 118:104213. doi: 10.1016/j.jml.2020.104213

Vainio, L., Mustonen, T., and Vainio, M. (2019c). The influence of number magnitude on vocal responses. J. Mot. Behav. 51, 129-140. doi: 10.1080/00222895.2018.1440522

Vainio, L., Rantala, A., Tiainen, M., Tiippana, K., Komeilipoor, N., and Vainio, M. (2017a). Systematic influence of perceived grasp shape on speech production. PLoS One 12:e0170221. doi: 10.1371/journal.pone.0170221

Vainio, L., Schulman, M., Tiippana, K., and Vainio, M. (2013). Effect of syllable articulation on precision and power grip performance. PLoS One 8:e53061. doi: 10.1371/journal.pone.0053061

Vainio, L., Tiainen, M., Tiippana, K., Komeilipoor, N., and Vainio, M. (2015). Interaction in planning movement direction for articulatory gestures and manual actions. Exp. Brain Res. 233, 2951-2959. doi: 10.1007/s00221-015-4365-y

Vainio, L., Tiainen, M., Tiippana, K., Rantala, A., and Vainio, M. (2017b). Sharp and round shapes of seen objects have distinct influences on vowel and consonant articulation. Psychol. Res. 81, 827-839. doi: 10.1007/ s00426-016-0778-x
Vainio, L., Tiainen, M., Tiippana, K., and Vainio, M. (2014). Shared processing of planning articulatory gestures and grasping. Exp. Brain Res. 232, 2359-2368. doi: 10.1007/s00221-014-3932-y

Vainio, L., Tiainen, M., Tiippana, K., and Vainio, M. (2019b). Connecting directional limb movements to vowel fronting and backing. Neurosci. Lett. 711:134457. doi: 10.1016/j.neulet.2019.134457

Vainio, L., Tiippana, K., Tiainen, M., Rantala, A., and Vainio, M. (2018). Reaching and grasping with the tongue: shared motor planning between hand actions and articulatory gestures. Q. J. Exp. Psychol. 71, 2129-2141. doi: $10.1177 / 1747021817738732$

Vainio, L., Vainio, M., Lipsanen, J., and Ellis, R. (2019a). The sound of grasp affordances: influence of grasp-related size of categorized objects on vocalization. Cogn. Sci. 43:e12793. doi: 10.1111/cogs.12793

Wagner, P., Malisz, Z., and Kopp, S. (2014). Gesture and speech in interaction: an overview. Speech Comm. 57, 209-232. doi: 10.1016/j.specom.2013.09.008

Wallace, A. R. (1881). Review of Tylor's anthropology. Nature 24, 242-245. doi: $10.1038 / 024242 \mathrm{a} 0$

Walsh, V. (2003). A theory of magnitude: common cortical metrics of time, space and quantity. Trends Cogn. Sci. 7, 483-488. doi: 10.1016/j.tics.2003.09.002

Whalen, D. H., and Levitt, A. G. (1995). The universality of intrinsic F0 of vowels. J. Phon. 23, 349-366. doi: 10.1016/S0095-4470(95)80165-0

Wichmann, S., Holman, E. W., and Brown, C. H. (2010). Sound symbolism in basic vocabulary. Entropy 12, 844-858. doi: 10.3390/e12040844

Winter, B., and Perlman, M. (2021). Iconicity ratings really do measure iconicity, and they open a new window onto the nature of language. Linguist. Vanguard 7. doi: 10.1515/lingvan-2020-0135

Wolpert, D. M., Ghahramani, Z., and Flanagan, J. R. (2001). Perspectives and problems in motor learning. Trends Cogn. Sci. 5, 487-494. doi: 10.1016/ S1364-6613(00)01773-3

Conflict of Interest: The authors declare that the research was conducted in the absence of any commercial or financial relationships that could be construed as a potential conflict of interest.

Publisher's Note: All claims expressed in this article are solely those of the authors and do not necessarily represent those of their affiliated organizations, or those of the publisher, the editors and the reviewers. Any product that may be evaluated in this article, or claim that may be made by its manufacturer, is not guaranteed or endorsed by the publisher.

Copyright (๑) 2021 Vainio and Vainio. This is an open-access article distributed under the terms of the Creative Commons Attribution License (CC BY). The use, distribution or reproduction in other forums is permitted, provided the original author(s) and the copyright owner(s) are credited and that the original publication in this journal is cited, in accordance with accepted academic practice. No use, distribution or reproduction is permitted which does not comply with these terms. 